Research Article

\title{
Investigation on the Electrothermal Properties of Nanocomposite HDPE
}

\author{
Ramkumar $\mathbf{R} \mathbb{D}^{1}$ and Pugazhendhi Sugumaran $\mathbf{C}^{2}$ \\ ${ }^{1}$ Division of High Voltage Engineering, College of Engineering Guindy, Anna University, Chennai, 600025 Tamil Nadu, India \\ ${ }^{2}$ Department of Electrical and Electronics Engineering, College of Engineering Guindy, Anna University, Chennai, \\ 600025 Tamil Nadu, India
}

Correspondence should be addressed to Ramkumar R; kumarram077@gmail.com

Received 31 January 2019; Revised 17 March 2019; Accepted 27 March 2019; Published 28 April 2019

Guest Editor: Laijun Liu

Copyright ( $) 2019$ Ramkumar R and Pugazhendhi Sugumaran C. This is an open access article distributed under the Creative Commons Attribution License, which permits unrestricted use, distribution, and reproduction in any medium, provided the original work is properly cited.

\begin{abstract}
Currently, several deep-rooted researches have focused on the significance and application of polymers in electrical and mechanical fields. This is because of the benefits of polymers in its availability, recyclability, and flexibility in processing; economical and most importantly improvement in material property have been achieved by incorporating nanosized metal oxide (inorganic) additives in the polymer matrix. In this study, HDPE (High Density Polyethylene) is considered as base polymer and alumina as nanoadditive. Alumina $\left(\mathrm{Al}_{2} \mathrm{O}_{3}\right)$ nanofillers are incorporated in HDPE as $1 \mathrm{wt} . \%, 3 \mathrm{wt} . \%, 5 \mathrm{wt} . \%$, and $7 \mathrm{wt} \%$ filler compositions. From the dielectric analysis, it has been inferred that HDPE with $3 \mathrm{wt} . \%$ nanoalumina achieved higher permittivity compared with other samples. Also, $5 \mathrm{wt} \%$ composite samples has gained $18.46 \%$ improvement in inception voltage, $16.3 \%$ increase in the breakdown strength, and $94.47 \%$ enhanced thermal conductivity compared with pure HDPE.
\end{abstract}

\section{Introduction}

Polymer dielectrics are nowadays widely used in electrical applications. The main objective of the experiments conducted was focused on creating new low cost polymeric composite material with better performance for electrical applications. Polymer dielectrics are mostly preferred based on its better electrical, thermal, and mechanical properties and for its flexibility while processing. Recently, most researches have acknowledged the necessity of incorporating the nanofillers in the polymer matrix to enhance the properties of dielectrics. The enhancement of the properties in dielectrics when nanofillers were incorporated in the polymer matrix has already been proved with many effective illustrations. Literature shows that the nanosized fillers have some unique properties like homogeneity in dispersion and distribution; it can establish better surface area of contact in the polymer matrix and has more interaction with host at a low level of loading. This feature is the major factor for the increased interaction zone, i.e., there is an increase in area between the filler and the polymer matrix, which has considerable impact on electrical insulation properties such as higher resistance towards partial discharge, treeing, and improvement in breakdown strength $[1-3]$.

The interaction zones are made of three layers, bounded layer, bound layer, and loose layer. The bounded layer is the first layer, which has the tight bonding with the inorganic nanofillers and the organic polymer matrix of few $\mathrm{nm}$ thickness. The second layer is the bound layer of several nanometer thickness, which interrelates the bounded layer and the nanoparticles. The third layer is the loose layer of several tens of nm thickness, which interacts with the second layer. There is another layer encompassing the third, an electronic double bond layer in which the columbic interaction of charges takes place. In this layer, charges are injected from the higher permittivity nanofillers into the polymer matrix (Gouy-Chapman diffusion layer), which induces the electronic polarizability and orientation of permanent dipoles. Many other factors have influenced on reduction 


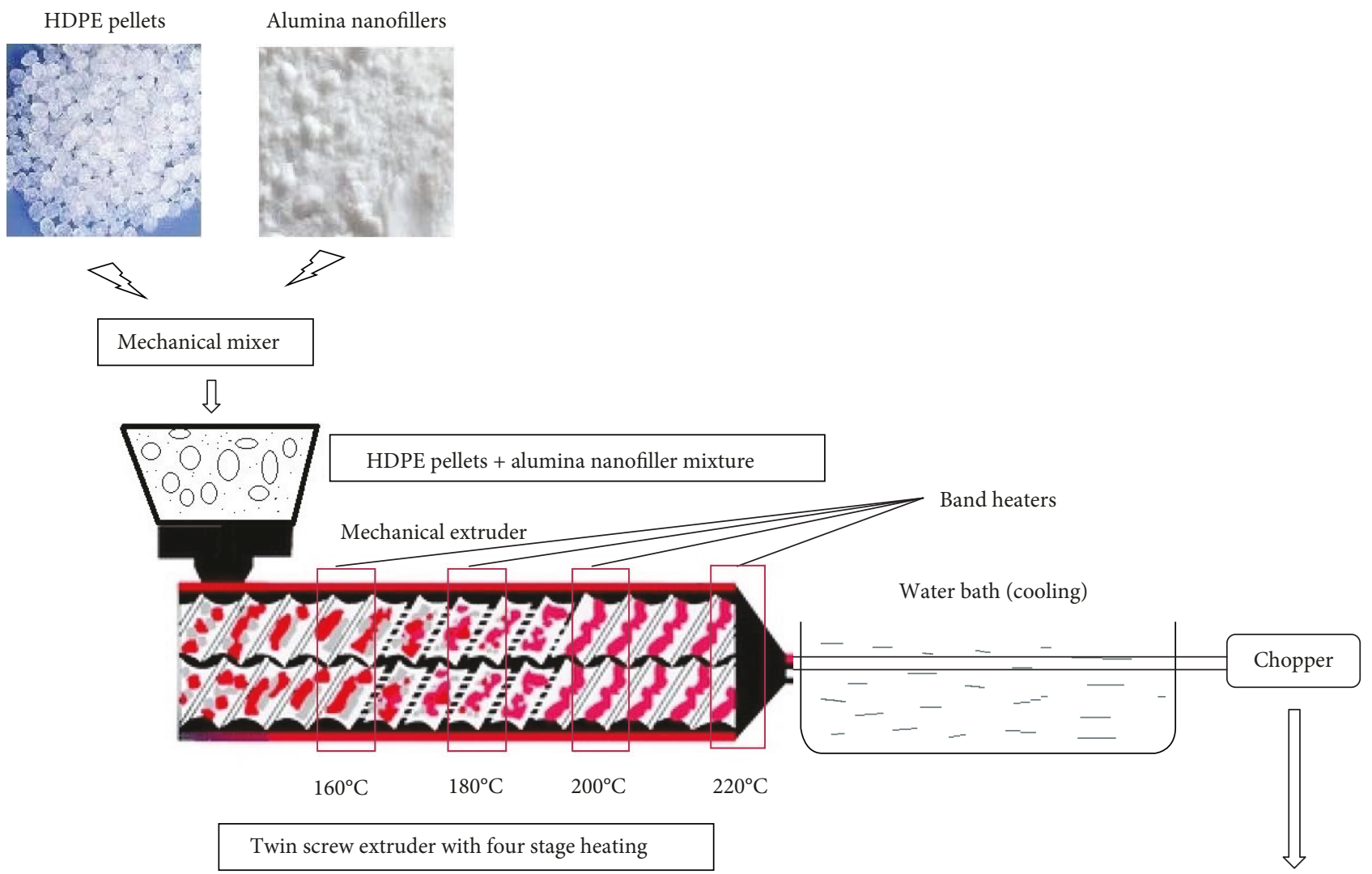

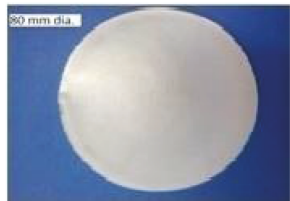

$80 \mathrm{~mm}$ dia.

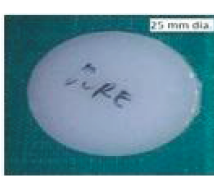

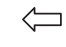

$25 \mathrm{~mm}$ dia.

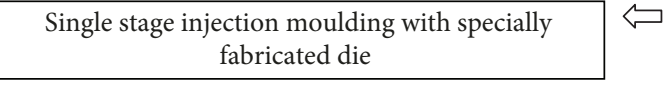

fabricated die

Prepared samples

FIGURE 1: Flow illustration for the melt blending process of HDPE-alumina nanocomposite.

in permittivity due to free volume and the higher energy surface contact of nanomaterial over the polymer matrix [4].

This work consists of various processes such as selection of materials, methodology of sample preparation, and experiments conducted on exploring the electrical and thermal performance of the prepared samples. Based on polymer segmental motion, permittivity and thermal stability of HDPE (High Density Polyethylene) have been chosen as base polymer and alumina $\left(\mathrm{Al}_{2} \mathrm{O}_{3}\right)$ as nanofillers. It had been evidently proven that nanosized alumina fillers offered high resistance for partial discharges and better dielectric and mechanical properties, while microsized alumina had been considered upright filler for enhancement of thermal conductivity [5].

\section{Experimental Work}

In this work, composition of FF00851 grade HDPE with MFI $9 \mathrm{~g} / 10 \mathrm{~min}$ from Haldia Corporation and nanosized alumina filler of size $<100 \mathrm{~nm}$ from SRL Chemicals were considered for sample preparation. The dielectric parameters such as permittivity, $\tan \delta$, and parallel resistance $R_{\mathrm{p}}$ have been measured using Electrochemical Impedance Spectroscopy WAYNE KERR 6500B. The value of AC breakdown strength was determined in AC breakdown setup as per standard IEC 60243-1. TGA (Thermogravimetric analysis) had been carried out in NETZSCH STA 449 F3 Jupiter, thermal analyzer (TA). The partial discharges (PD) for the prepared samples were examined using the PD setup as per standard IEC 60270, 2003.

2.1. Sample Preparation. The various processes involved in the sample preparation are illustrated in Figure 1. The handmade mechanical extrusion technology is opted for sample preparation, which is of environment friendly nature. The temperatures of heaters in the screw mixture barrel are maintained at $160^{\circ} \mathrm{C}, 180^{\circ} \mathrm{C}, 200^{\circ} \mathrm{C}$, and $220^{\circ} \mathrm{C}$ [6]. The extruded materials are molded into a die with injection molding machine. 
Table 1 shows the composition of HDPE and nanoalumina for a $100 \mathrm{~g}$ samples at different wt.\%. Samples of $25 \mathrm{~mm}$ diameter and $3 \mathrm{~mm}$ thickness are prepared for dielectric measurements, and another sample of $80 \mathrm{~mm}$ diameter with $1.5 \mathrm{~mm}$ thickness is prepared for AC breakdown (IEC 60243-1) and PD measurement.

2.2. Scanning Electron Microscopy. The morphology of HDPE/alumina nanocomposites for different weight composition was analyzed. The homogeneous dispersion and distribution of alumina nanoparticles in HDPE at $1 \mathrm{wt} . \%$, 3 wt. $\%$, 5 wt. $\%$, and 7 wt. $\%$, respectively, are presented by SEM image from Figures 2(a)-2(d), the alumina nanoparticles are uniformly distributed in the HDPE matrix. The particle sizes are at most around $100 \mathrm{~nm}$. Few agglomerates can be also observed at $7 \mathrm{wt} . \%$ samples [7].

2.3. Partial Discharge. The PD resistance measurement setup as shown in Figure 3 was created as per IEC 60270 with a background noise of $4 \mathrm{pC}$ inside the shielding chamber. The measured value of PD inception and extinction voltages was recorded with the help of DSO Agilent 54621A and was tabulated in Table 2 .

It has been observed that the addition of nanofiller in the base polymer increases the PD resistance of the samples. There is likely to be strong bonding between the homogeneously dispersed alumina nanoparticles and the HDPE polymer which offers higher resistance to the stress on applying electric field, as a result the PD resistance of the composite increases. It has been noticed that for higher wt.\% of nanoalumina added samples, the space in the interfacial zone increases thus reducing the PD resistance of the samples $[3,8-10]$. The maximum inception and extinction voltages observed for $5 \mathrm{wt}$.\% samples with a rise of $18.46 \%$ and $35.79 \%$, respectively, in comparison with pure HDPE samples.

2.4. AC Breakdown Strength. AC breakdown strength was determined for the prepared samples of HDPE along with $1,3,5$, and $7 \mathrm{wt} \%$ nanoalumina at power frequencies (50-60) $\mathrm{Hz}$ with reference to IEC 60243-1. An average of 10 samples from each composition was tested, and the mean value had been considered for the analysis. The test specimen was immersed in the insulating liquid medium with higher dielectric strength in order to avoid the surface flashover and gliding discharges at the edges [11].

The values of the breakdown strength for different samples obtained were listed in Table 3. It was observed that $5 \mathrm{wt} . \%$ composition of alumina with HDPE has attained $16.3 \%$ increased breakdown strength compared with pure HDPE.

The characteristics on the enhancement of breakdown strength of the samples based on the effect of alumina nanofillers and the diminution at higher wt.\% concentrations of nanofillers are illustrated as follows: (a) nanoparticles act as a scattering electron source, which avoid the formation of a spheroid mass of crystals and macroscopic boundaries. Nanoparticles are high resistance towards PD. (b) There will be a large amount of charge traps at the interfacial region,
TABLE 1: Weight composition of different samples.

\begin{tabular}{lcc}
\hline $\begin{array}{l}\text { wt.\% composition of } \\
\text { alumina with HDPE }\end{array}$ & HDPE in grams & Nanoalumina in grams \\
\hline 0 & 100 & 0 \\
1 & 99.009 & 0.9900 \\
3 & 97.0873 & 0.9708 \\
5 & 95.2380 & 4.7619 \\
7 & 93.4579 & 6.5420 \\
\hline
\end{tabular}

which decreases the carrier charge mobility. (c) At higher wt.\%, agglomeration of nanoparticles takes place which leads to creation of large void defects around it in the polymer matrix. (d) The higher permittivity agglomerated nanoparticles alter an electric field and reduce the space between nanoparticles, which create a conductive path by enhancing the tunneling current between nanofillers. Figure 4 represents the mean and error bar of breakdown voltage (BDV) and Partial Discharge Inception Voltage (PDIV). It can be clearly observed on the BDV that the error bars for each samples does not overlap on each other; thus, the error bars are not different for each samples, but for PDIV, the error bars for the 3 wt.\% sample show minimal value. These results also indicate that the $\mathrm{BD}$ occurs after the occurrence of $\mathrm{PD}$. Further, error bars for AC breakdown strength clearly show that HDPE with 5 wt.\% alumina has the highest mean with good breakdown strength.

2.5. Dielectric Constant and Loss Factor. The dielectric parameters had been recorded for all composition of samples at $30^{\circ} \mathrm{C}, 60^{\circ} \mathrm{C}, 90^{\circ} \mathrm{C}$, and $120^{\circ} \mathrm{C}$ temperatures and as a function of frequency from $20 \mathrm{~Hz}-1 \mathrm{MHz}$ by using the Impedance Analyzer. The real part of dielectric constant $(\varepsilon)$ had been calculated from the recorded value of capacitance, from

$$
\varepsilon=\frac{t * C_{p}}{A * \varepsilon_{0}},
$$

where $C_{p}$ is the capacitance in farads, $t$ is the thickness of the sample in meters (m), $A$ is the surface area of samples in sq. meters, and $\varepsilon_{0}$ is the absolute permittivity.

Figures $5(\mathrm{a})-5(\mathrm{~d})$ represent the variation of dielectric constant $(\varepsilon)$ with respect to frequency for the prepared nanocomposite samples at $30,60,90$, and $120^{\circ} \mathrm{C}$ temperatures. It is observed that

(a) permittivity usually increases, as a result of incorporating higher permittivity inorganic fillers in the polymer matrix, which initiates the interfacial polarization of the Maxwell-Wagner type. In addition, it was confirmed with the Lichtenecker-Rother logarithmic law of mixing

(b) as the frequency of AC supply varied, initially the $\varepsilon$ is invariable, but at a certain critical frequency, the polarization of ions gets saturated or failed to settle; thus, the $\varepsilon$ value dropped at lower to higher frequencies 


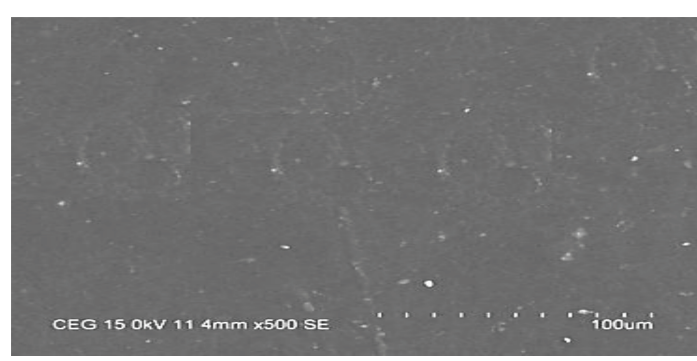

(a)

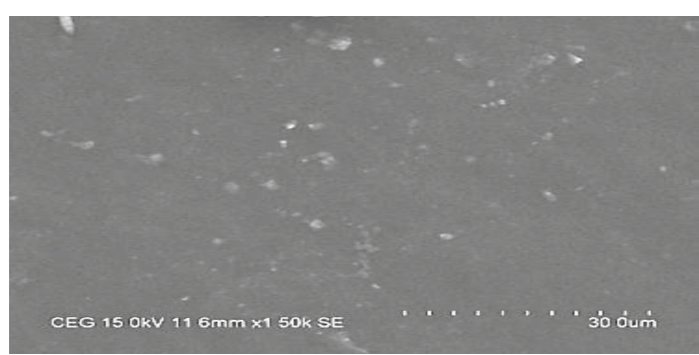

(c)

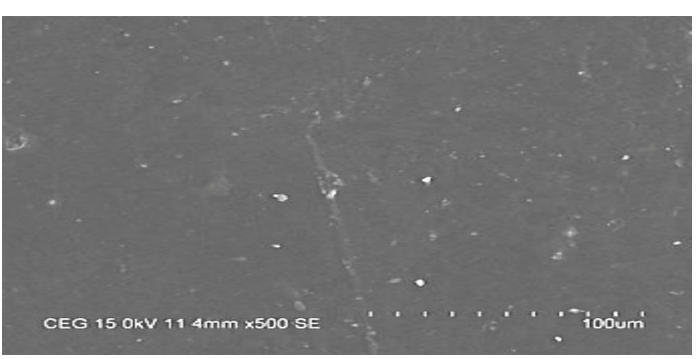

(b)

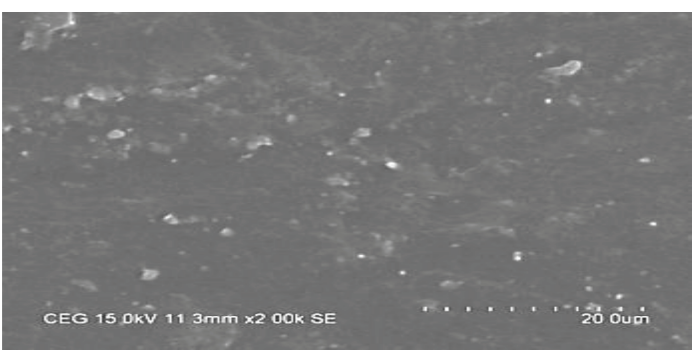

(d)

Figure 2: (a)-(d) SEM image of HDPE-alumina nanocomposite: (a) @ 1 wt.\%, (b) @ 3 wt.\%, (c) @ 5 wt.\%, and (d) @ 7 wt.\%.

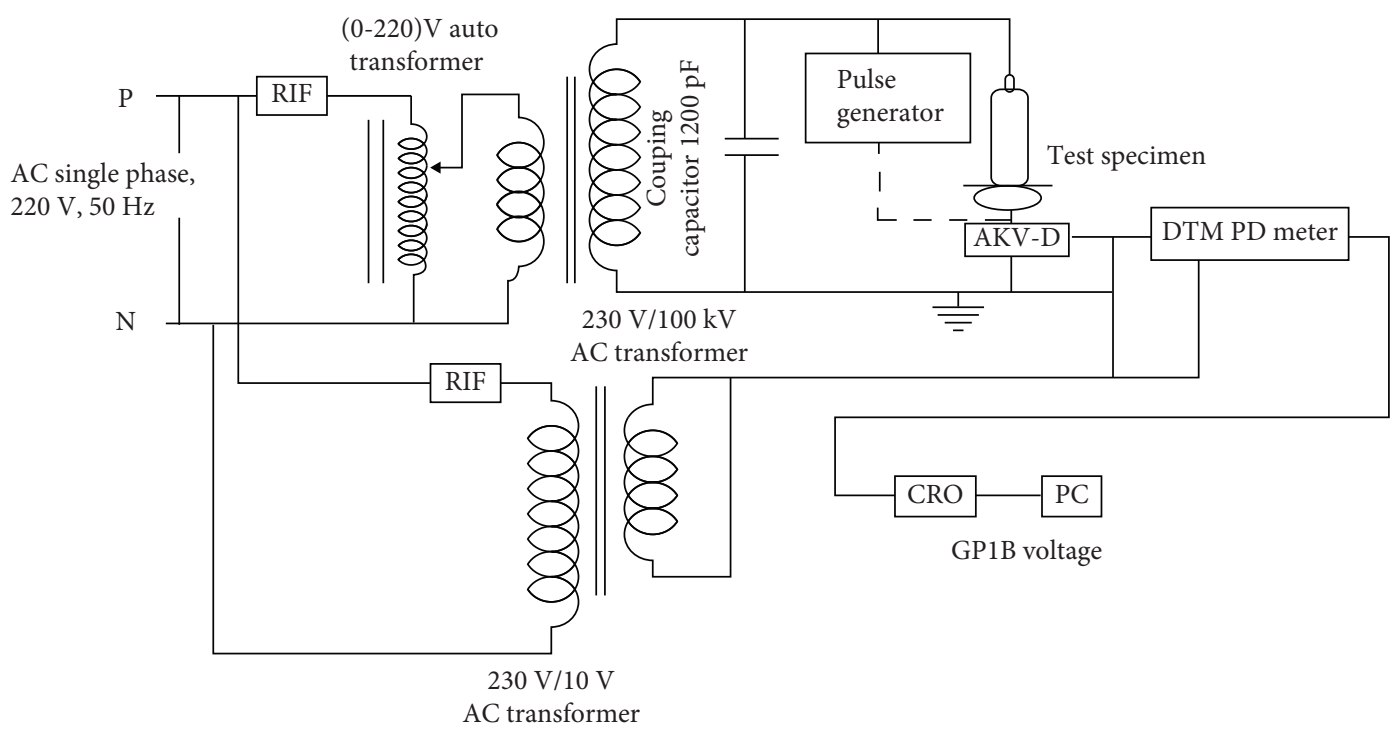

Figure 3: Partial discharge setup.

TABle 2: Partial discharge characteristics.

\begin{tabular}{lcc}
\hline Sample & $\begin{array}{c}\text { Inception voltage } \\
(\mathrm{kV} / \mathrm{mm})\end{array}$ & $\begin{array}{c}\text { Extinction voltage } \\
(\mathrm{kV} / \mathrm{mm})\end{array}$ \\
\hline Pure HDPE & 18.97 & 13.52 \\
HDPE with 1 wt.\% alumina & 19.34 & 13.84 \\
HDPE with 3 wt.\% alumina & 20.32 & 14.074 \\
HDPE with 5 wt.\% alumina & 22.473 & 18.36 \\
HDPE with 7 wt.\% alumina & 21.542 & 17.615 \\
\hline
\end{tabular}

(c) there was no significant variation in the permittivity at lower temperatures; it was due to high density of the polyethylene matrix, which disturbed the charge
TABLE 3: AC breakdown strength (BDV).

\begin{tabular}{lcc}
\hline Sample & AC BDV $(\mathrm{kV} / \mathrm{mm})$ & \% increase \\
\hline Pure HDPE & 28.18 & - \\
HDPE with 1 wt.\% alumina & 28.56 & 1.34 \\
HDPE with 3 wt.\% alumina & 29.32 & 4.04 \\
HDPE with 5 wt.\% alumina & 32.79 & 16.3 \\
HDPE with 7 wt.\% alumina & 30.44 & 8.01 \\
\hline
\end{tabular}

mobility at lower temperatures. The increase in temperature on the samples from $30^{\circ} \mathrm{C}$ to $120^{\circ} \mathrm{C}$ was noticed; there was an increase in its free volume 


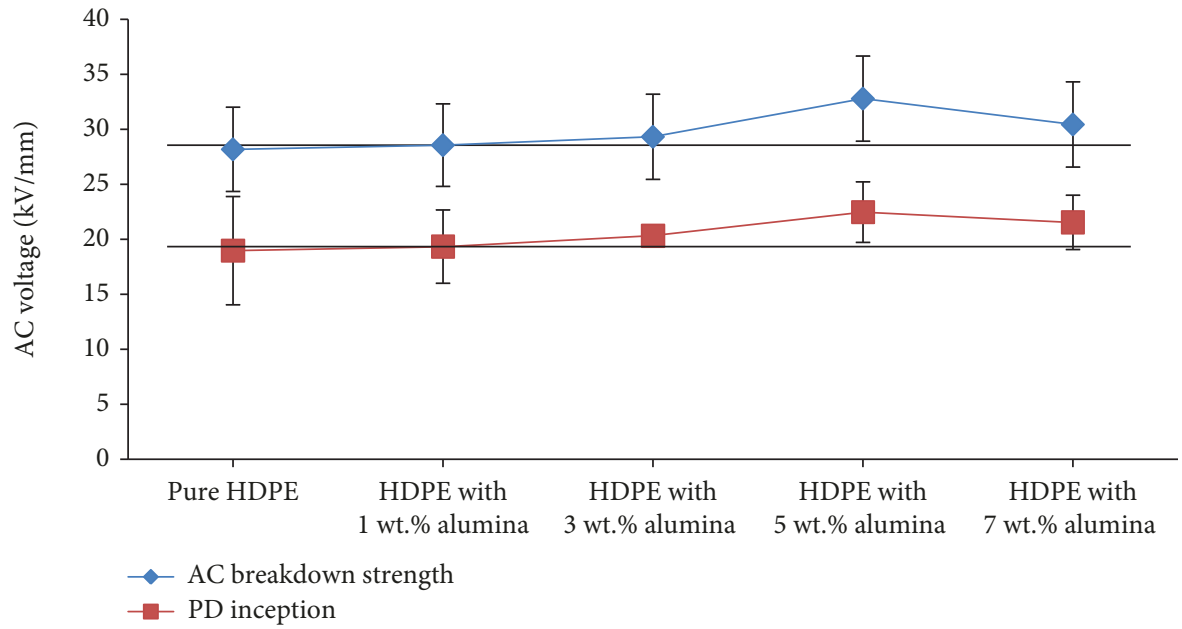

FIGURE 4: Error bar representing breakdown voltage (BDV) and Partial Discharge Inception Voltage (PDIV).

and thereby increasing the permittivity of the samples. The permittivity is inconsistent beyond $120^{\circ} \mathrm{C}$. The collapsing state of the polymer matrix during initiation of melting process (the melting point of the HDPE used in the work was $130^{\circ} \mathrm{C}$ ) causes the inconsistency in $\varepsilon$ [12]

(d) it was observed that the $3 \mathrm{wt} . \%$ composite sample attained higher permittivity with more filler content, which increased the ionic and electronic polarization in addition to the free dipoles of HDPE. Further increase in the filler content (i.e., at $7 \mathrm{wt} . \%$ ) led to more agglomeration of nanofillers forming clusters/ microstructures, thus reduction in free volume and therefore will be few dipoles and ionic carriers available in the outer layer not free to move; thus, there is reduction in permittivity

Figures 6(a)-6(d) represent the dielectric loss $(\tan \delta$ ) vs. the frequency plot for different weight compositions of nanoalumina on HDPE at different temperatures. It was resolved that

(a) dissipation factor was influenced by the filler loadings and permittivity. In polymer nanocomposites, due to polarization effect, the dipoles in interfacial zones create clusters. There was a setback in orientation of dipoles, which reverses in each cycle on the application of alternating field. At higher frequencies, the dielectric loss might be increased with an effect of speedy reversal of field and orientation of dipoles would lag the field. The less time to orient dipoles among themselves led to a rise of dielectric loss in the higher frequency

(b) at higher frequencies beyond $1 \mathrm{kHz}$, the $\tan \delta$ had been observed to be less than unity. The $\tan \delta$ increased with an increase in temperature and decreased at high frequencies (c) addition of alumina nanofillers had an influence over the dielectric loss of the composite. The higher wt.\% of filler content increased the charge carrier which led to more amount of dielectric loss by charge transport mechanism. The $5 \mathrm{wt} . \%$ composition substantiated the $\tan \delta$ loss at lower frequencies for its better performance $[13,14]$

(d) at higher temperatures and frequencies between 50 and $1000 \mathrm{~Hz}$, there was a considerable increase of $\tan \delta$ loss in the 5 wt.\% composition. At high temperatures, the permittivity increase in free volume enhanced the ionic polarization, which caused more loss. Above than $1 \mathrm{kHz}$, there was no considerable difference in the $\tan \delta$ loss even at different temperatures

(e) the $\tan \delta$ losses at $50 \mathrm{~Hz}$ frequency varied from 0.67 to 0.77 for $5 \mathrm{wt} . \%$ samples with temperatures between 50 and $110^{\circ} \mathrm{C}$ and reaches the maximum around 150 to $170 \mathrm{~Hz}$ for $30^{\circ} \mathrm{C}, 60^{\circ} \mathrm{C}, 90^{\circ} \mathrm{C}$, and $120^{\circ} \mathrm{C}$

2.6. Volume Resistivity. The volume resistivity $(\rho)$ of pure HDPE and 1, 3, 5, and $7 \mathrm{wt} . \%$ nanoalumina samples was obtained from the measured value of parallel resistance $\left(R_{\mathrm{p}}\right)$.

The calculated values are plotted against frequencies in Figure 7. It was observed that at lower frequencies the $5 \mathrm{wt} . \%$ sample attains higher volume resistivity and was also noticed that the resistivity of all the samples linearly decreases up to $100 \mathrm{~Hz}$. Further, $100 \mathrm{~Hz}-10 \mathrm{kHz}$ the resistivity showed a constant value. The addition of alumina nanofillers reduced the volume resistivity, which averted the movement of charge carriers. On the application of AC fields, at lower frequencies, there was a considerable time for the charged particles, which had created weak links between nanofillers and HDPE segments. It resulted with a linear drop in volume resistivity when the conduction current at lower frequencies was increased. At higher 


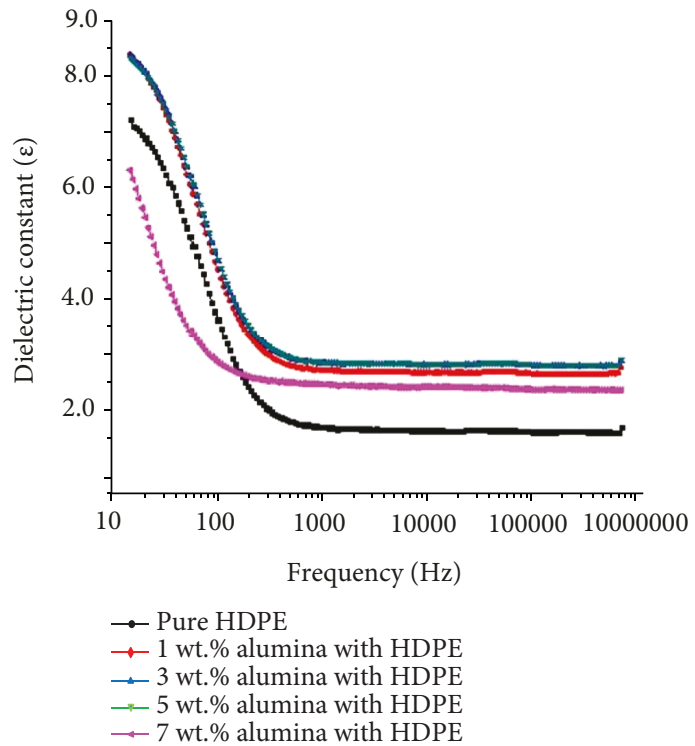

(a)

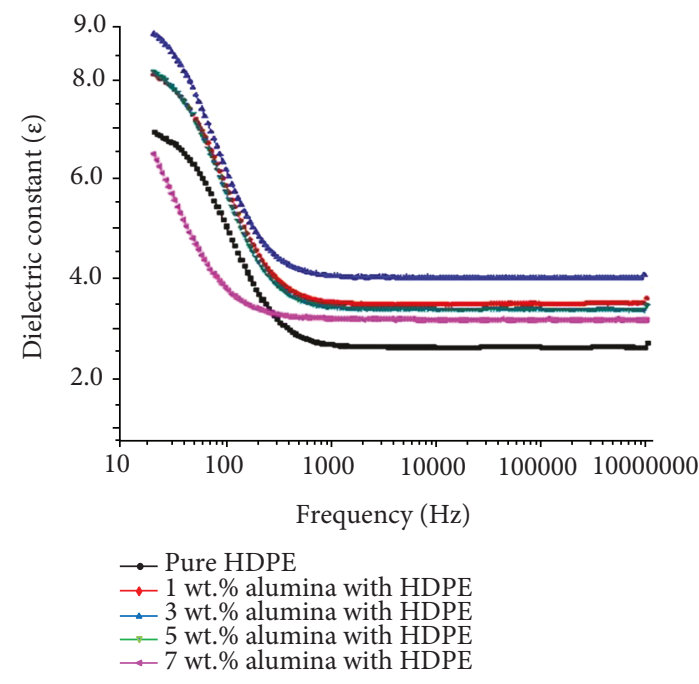

(c)

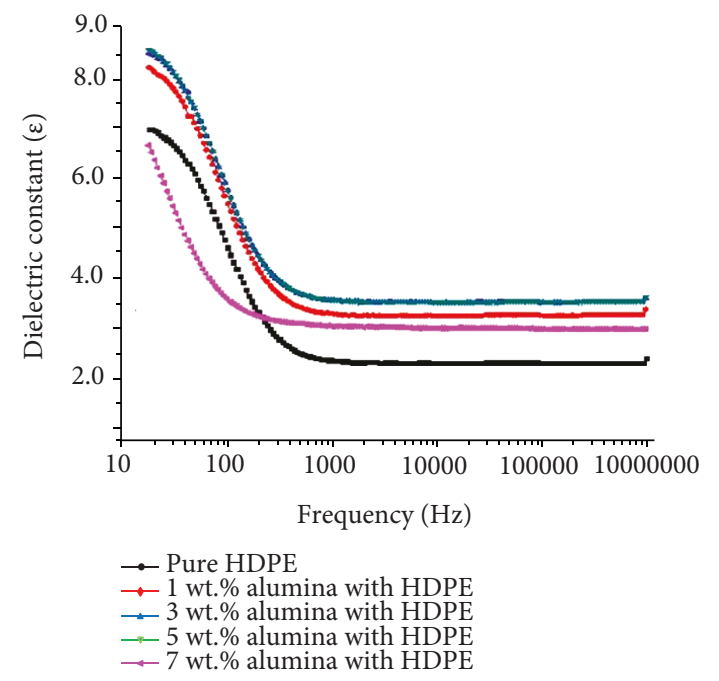

(b)

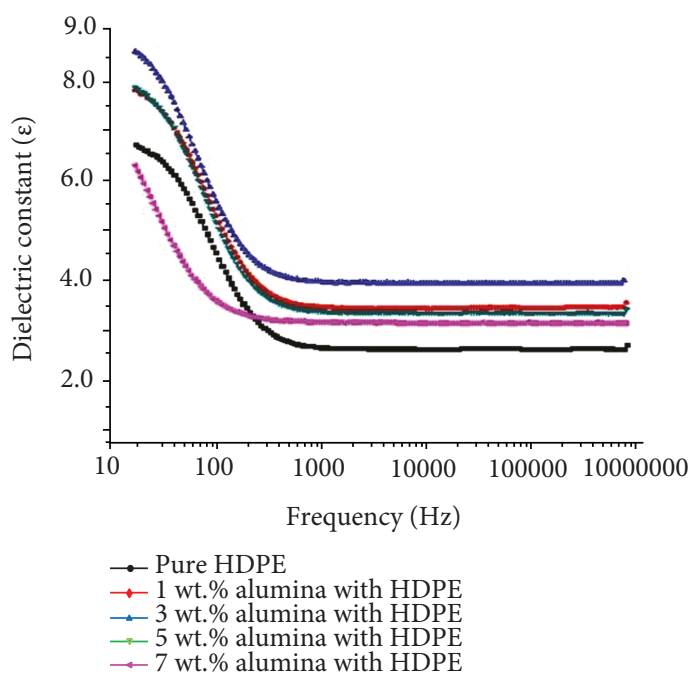

(d)

Figure 5: (a)-(d) Dielectric constant dependence on frequency: (a) @ 30 $\mathrm{C}$, (b) @ 60 $\mathrm{C}$, (c) @ $90^{\circ} \mathrm{C}$, and (d) @ $120^{\circ} \mathrm{C}$.

frequencies, the movement of the charged particle is restricted, which in turn reduces the conduction current without any significant change in the volume resistivity [15].

2.7. Thermal Conductivity. The thermal conductivity was measured using UNITHERM (model 2022) with reference to ASTM E1530. The sample was placed between two polished surfaces, the upper electrode was maintained at higher temperature and the lower electrode was calibrated with heat flow transducer at lower temperature. The heat flowed from the upper surface, establishing an axial temperature gradient in the stack for attaining thermal equilibrium state. The difference of temperature had been measured through the heat flow transducer.

The thermal conductivity was calculated for the samples by considering the transducer output and sample size. The calculated thermal conductivity values for different samples are listed in Table 4.

Equation (2) represents the heat dissipated by the solid dielectrics on the application of AC fields,

$$
\mathrm{HD}=C_{v} \frac{d T}{d t}+\Lambda \cdot(K \operatorname{grad} T)
$$

where $\mathrm{HD}$ is the heat dissipated, $C_{v}$ is the specific heat of the sample, $T$ is the temperature of the sample, $K$ is the thermal conductivity of the sample, and $t$ is the time for heat dissipation. The higher thermal conductivity indicated the more heat dissipation. From Figure 6(d), it was ascertained that 3 wt. $\%$ and 5 wt.\% samples accomplished the higher dissipation factor by having higher mobility of ions. From Table 4, it was seen that the higher thermal conductivity helps to 

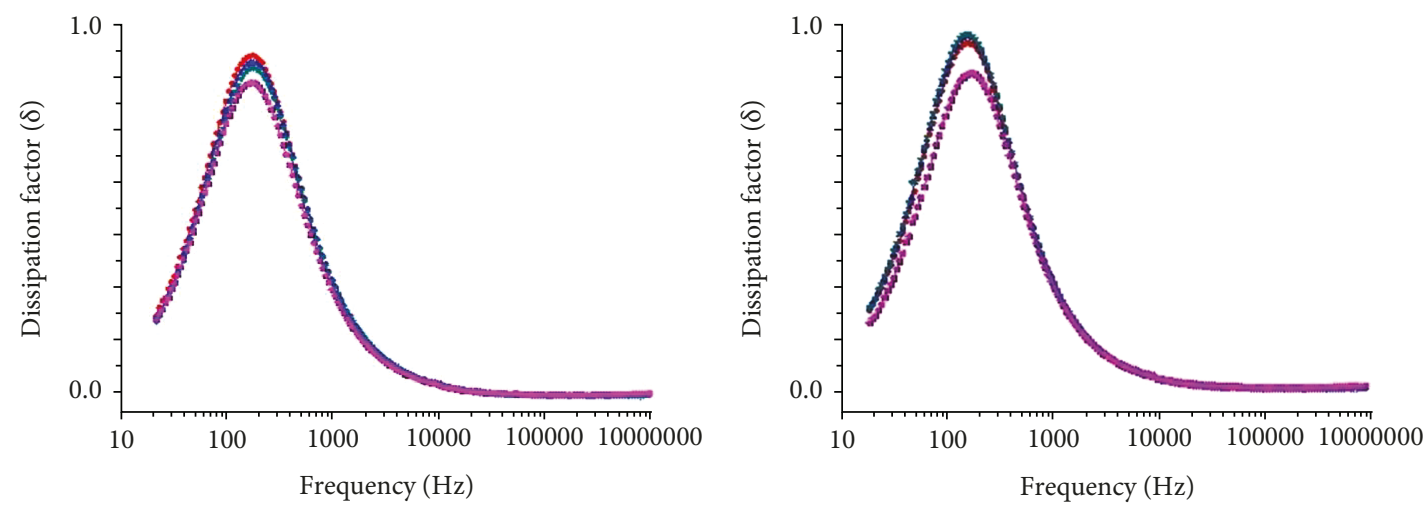

$\rightarrow$ - Pure HDPE

$\rightarrow 1$ wt.\% alumina with HDPE

$\rightarrow 3 \mathrm{wt}$ \% alumina with HDPE

$\rightarrow-5$ wt.\% alumina with HDPE

$\leftarrow 7$ wt.\% alumina with HDPE

(a)

$\rightarrow$ Pure HDPE

$\rightarrow 1$ wt.\% alumina with HDPE

$\rightarrow 3$ wt.\% alumina with HDPE

$\rightarrow-5$ wt.\% alumina with HDPE

$\leftarrow 7$ wt.\% alumina with HDPE

(b)
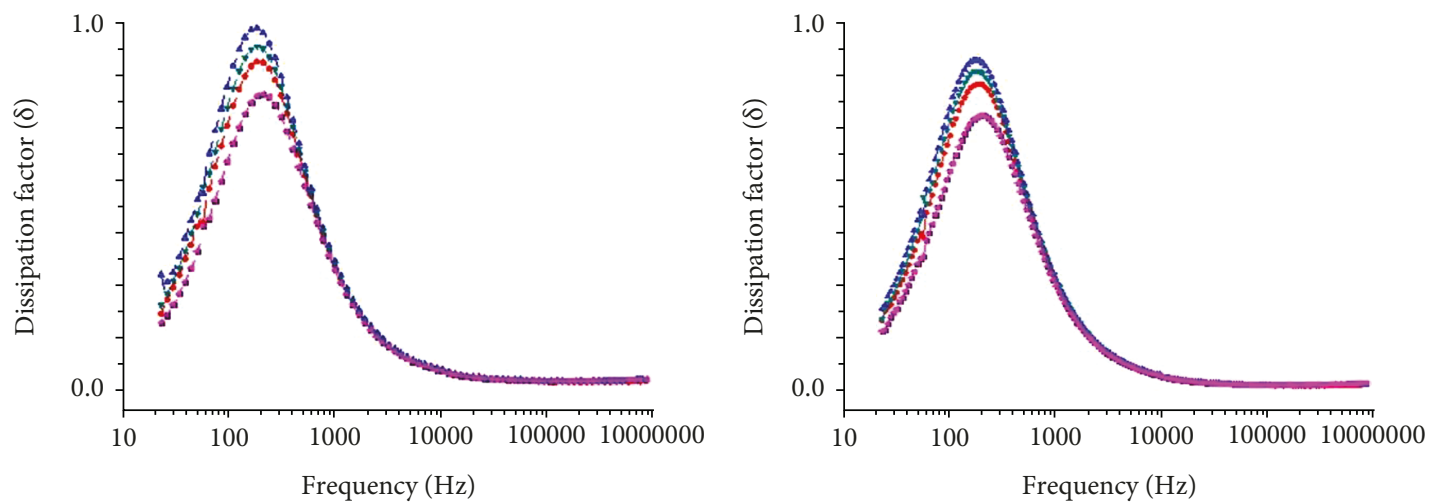

$\rightarrow$ Pure HDPE

$\rightarrow 1$ wt.\% alumina with HDPE

- 3 wt.\% alumina with HDPE

$-5 \mathrm{wt} \%$ alumina with HDPE

$\hookrightarrow 7$ wt.\% alumina with HDPE

(c)

$\rightarrow$ Pure HDPE

$\rightarrow 1$ wt.\% alumina with HDPE

$\rightarrow 3$ wt.\% alumina with HDPE

-5 wt.\% alumina with HDPE

$\leftarrow 7$ wt.\% alumina with HDPE

(d)

Figure 6: (a)-(d) Dissipation factor $(\tan \delta)$ dependence on frequency $(\mathrm{Hz})$ : (a) @ 30 $\mathrm{C}$, (b) @ 60 $\mathrm{C}$, (c) @ $90^{\circ} \mathrm{C}$, and (d) @ $120^{\circ} \mathrm{C}$.

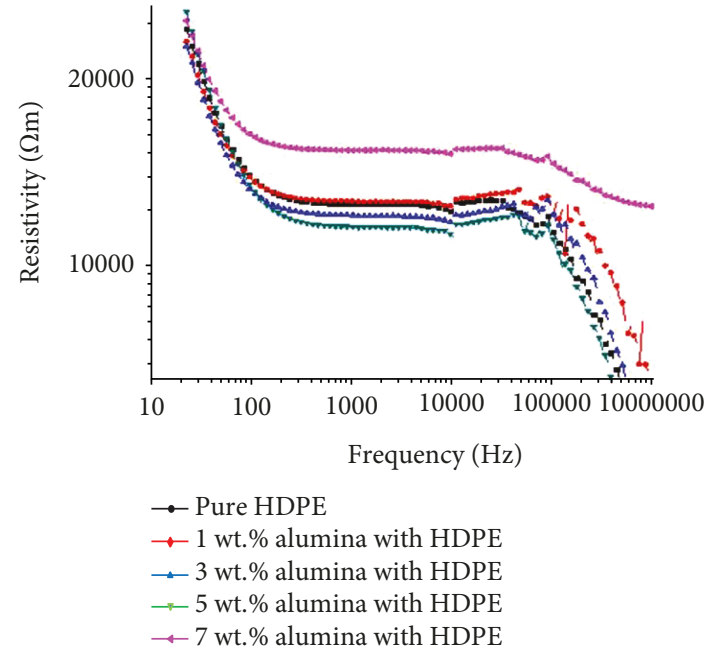

Figure 7: Resistivity $(\Omega \cdot \mathrm{m})$ dependence on frequency $(\mathrm{Hz})$.
TABLE 4: Thermal conductivity.

\begin{tabular}{lcc}
\hline Sample & $\begin{array}{c}\text { Thermal conductivity } \\
(\mathrm{W} / \mathrm{m} \cdot \mathrm{K})\end{array}$ & $\begin{array}{c}\% \\
\text { increase }\end{array}$ \\
\hline Pure HDPE & 0.471 & - \\
HDPE with 1 wt.\% alumina & 0.525 & 11.46 \\
HDPE with 3 wt.\% alumina & 0.712 & 51.16 \\
HDPE with 5 wt.\% alumina & 0.916 & 94.47 \\
HDPE with 7 wt.\% alumina & 0.919 & 95.11 \\
\hline
\end{tabular}

attain the thermal equilibrium of sample, which supports to enhance the dielectric strength as shown in Table 3 with respect to the $5 \mathrm{wt} . \%$ sample (thermal $\mathrm{BD}$ ).

2.8. Thermogravimetric Analysis. The TA Instrument TGA Q50 V20.13 Build 39 was used to record the change in weight of the samples with respect to temperature at the rate of rise 


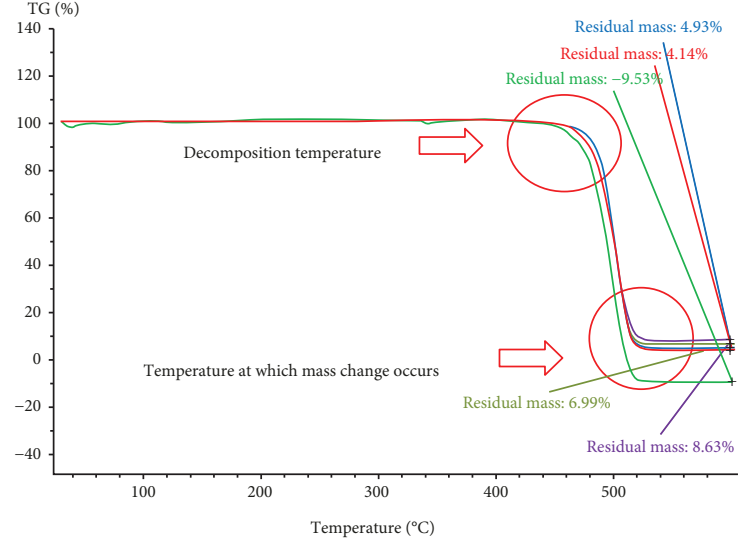

[1] G Pure 30to600@20Min 2303 2017.ngb-ds
TG
[2] G1\% 30to600@20Min 2303 2017.ngb-ds3
TG
[3] G3\% 30to600@20Min 2303 2017.ngb-ds3
TG
[4] G5\% 30to600@20Min 2303 2017.ngb-ds3
TG
[5] G7\% 30to600@20Min 2303 2017.ngb-ds3

Figure 8: TGA comparison of pure HDPE: 1 wt.\%, 3 wt.\%, 5 wt.\%, and 7 wt.\% samples.

of $20^{\circ} \mathrm{C} /$ minute in the nitrogen atmosphere (dynamic TGA). The thermogram was recorded from $40^{\circ} \mathrm{C}$ to $600^{\circ} \mathrm{C}$. The results were analyzed for validating the purity, rate of reaction, activation energy, heat reaction, and identification of different composition of the samples [16].

From the thermogram shown in Figure 8, it was observed that the pure HDPE sample starts to decompose at $460^{\circ} \mathrm{C}$. It was ascertained from the TGA that the pure sample exhausted at $520^{\circ} \mathrm{C}$. The $1,3,5$, and 7 samples had $4.14 \%$, $4.93 \%, 6.99 \%$, and $8.63 \%$ residues, respectively, recorded at $600^{\circ} \mathrm{C}$. The $7 \mathrm{wt} . \%$ sample had higher amount of residue at $600^{\circ} \mathrm{C}$ due to higher thermal conductivity.

\section{Conclusion}

This paper exhibits the detailed study on the electrical and thermal behaviour of the HDPE by the addition of alumina nanofillers. Summary of the observations made is listed as follows: the $5 \mathrm{wt} . \%$ HDPE/alumina composite had obtained $16 \%$ higher $\mathrm{AC}$ breakdown strength in comparison with pure HDPE sample. The $3 \mathrm{wt} . \%$ composition gained higher permittivity for $20-400 \mathrm{~Hz}$ at $30^{\circ}, 60^{\circ}, 90^{\circ}$, and $120^{\circ} \mathrm{C}$.

From PD results, it has been proven that the addition of inorganic alumina nanofillers to HDPE significantly improved the PD characteristic. This has happened as a result of strong bonding between nanoparticles and the HDPE at the interfacial region.

With the increased filler loading content, there was a weak link formation resulted in a decline in volume resistivity. The glass transition temperature of the $5 \mathrm{wt} . \%$ composition was observed as $121^{\circ} \mathrm{C}$ which was $23.4 \%$ higher than pure HDPE. Higher thermal conductivity of the specimen helped to attain the thermal equilibrium, which further enhanced the breakdown voltage.
For insulation applications, the HDPE with $5 \mathrm{wt} . \%$ alumina was considered as it had improved the breakdown strength and thermal stability.

\section{Data Availability}

The data used to support the findings of this study are available from the corresponding author upon request.

\section{Conflicts of Interest}

The authors declare that there is no conflict of interest regarding the publication of this paper.

\section{References}

[1] V. A. Zakrevskii, N. T. Sudar, A. Zaopo, and Y. A. Dubitsky, "Mechanism of electrical degradation and breakdown of insulating polymers," Journal of Applied Physics, vol. 93, no. 4, pp. 2135-2139, 2003.

[2] J. K. Nelson and Y. Hu, "Nanocomposite dielectrics-properties and implications," Journal of Physics D: Applied Physics, vol. 38, no. 2, pp. 213-222, 2005.

[3] W. A. Izzati, Y. Z. Arief, Z. Adzis, and M. Shafanizam, "Partial discharge characteristics of polymer nanocomposite materials in electrical insulation: a review of sample preparation techniques, analysis methods, potential applications, and future trends," The Scientific World Journal, vol. 2014, Article ID 735070, 14 pages, 2014.

[4] T. Tanaka, M. Kozako, N. Fuse, and Y. Ohki, "Proposal of a multi-core model for polymer nanocomposite dielectrics," IEEE Transactions on Dielectrics and Electrical Insulation, vol. 12, no. 4, pp. 669-681, 2005.

[5] Y. Okazaki, M. Kozako, M. Hikita, and T. Tanaka, "Effects of addition of nano-scale alumina and silica fillers on thermal conductivity and dielectric strength of epoxy/alumina microcomposites," in IEEE International Conference on Solid Dielectrics, pp. 1-4, Potsdam, Germany, July 4-9, 2010.

[6] R. Ramkumar and C. P. Sugumaran, "Investigation on dielectric properties of HDPE with alumina nano fillers," in IEEE sponsored Power India conference (PIICON), pp. 1-4, Bikaner, India, November 25-27, 2016.

[7] M. Hajian, G. A. Koohmareh, and A. Mostaghasi, "Investigation of the effects of titanate as coupling agent and some inorganic nanoparticles as fillers on mechanical properties and morphology of soft PVC," International Journal of Polymer Science, vol. 2011, Article ID 238619, 9 pages, 2011.

[8] T. Imai, F. Sawa, T. Ozaki et al., "Influence of temperature on mechanical and insulation properties of epoxy-layered silicate nanocomposite," IEEE Transactions on Dielectrics and Electrical Insulation, vol. 13, no. 2, pp. 445-452, 2006.

[9] G. Zhang, G. Wu, L. Tong, and E. He, "Study of nano $\mathrm{TiO}_{2}$ filler in the corona-resistant magnetic wire insulation performance of inverter-fed motor," in Proceedings of 2005 International Symposium on Electrical Insulating Materials, pp. 180183, Kitakyushu, Japan, June 2005.

[10] C. P. Sugumaran, "Experimental investigation on dielectric and thermal characteristics of nanosized alumina filler added polyimide enamel," Journal of Electrical Engineering and Technology, vol. 9, no. 3, pp. 978-983, 2014. 
[11] L. Liu, L. Weng, Y. Song, L. Gao, and Q. Lei, "The effects of coupling agents on the properties of polyimide/nano$\mathrm{Al}_{2} \mathrm{O}_{3}$ three-layer hybrid films," Journal of Nano Materials, vol. 2010, Article ID 354364, 5 pages, 2010.

[12] B. Tareev, Physics of Dielectric Materials, Mir Publishers, Moscow, 2nd edition, 1979.

[13] C. Sugumaran, M. Mohan, and K. Udayakumar, "Investigation of dielectric and thermal properties of nano-filler $\left(\mathrm{ZrO}_{2}\right)$ mixed enamel," IEEE Transactions on Dielectrics and Electrical Insulation, vol. 17, no. 6, pp. 1682-1686, 2010.

[14] F. Madidi, G. Momen, and M. Farzaneh, "Dielectric properties of $\mathrm{TiO}_{2}$ /silicone rubber micro- and nanocomposites," Advances in Materials Science and Engineering, vol. 2018, Article ID 4682076, 7 pages, 2018.

[15] Y. Mobarak, M. Bassyouni, and M. Almutawa, "Materials selection, synthesis, and dielectrical properties of PVC nanocomposites," Advances in Materials Science and Engineering, vol. 2013, Article ID 149672, 6 pages, 2013.

[16] P. C. Irwin, Y. Cao, A. Bansal, and L. Schadler, "Thermal and mechanical properties of polyimide nanocomposites," in 2003 Annual Report Conference on Electrical Insulation and Dielectric Phenomena, pp. 120-123, Albuquerque, NM, USA, 2003. 


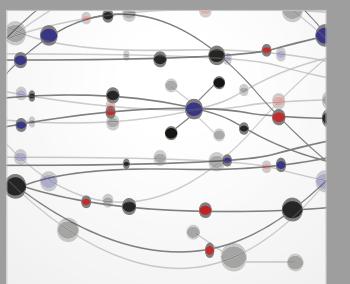

The Scientific World Journal
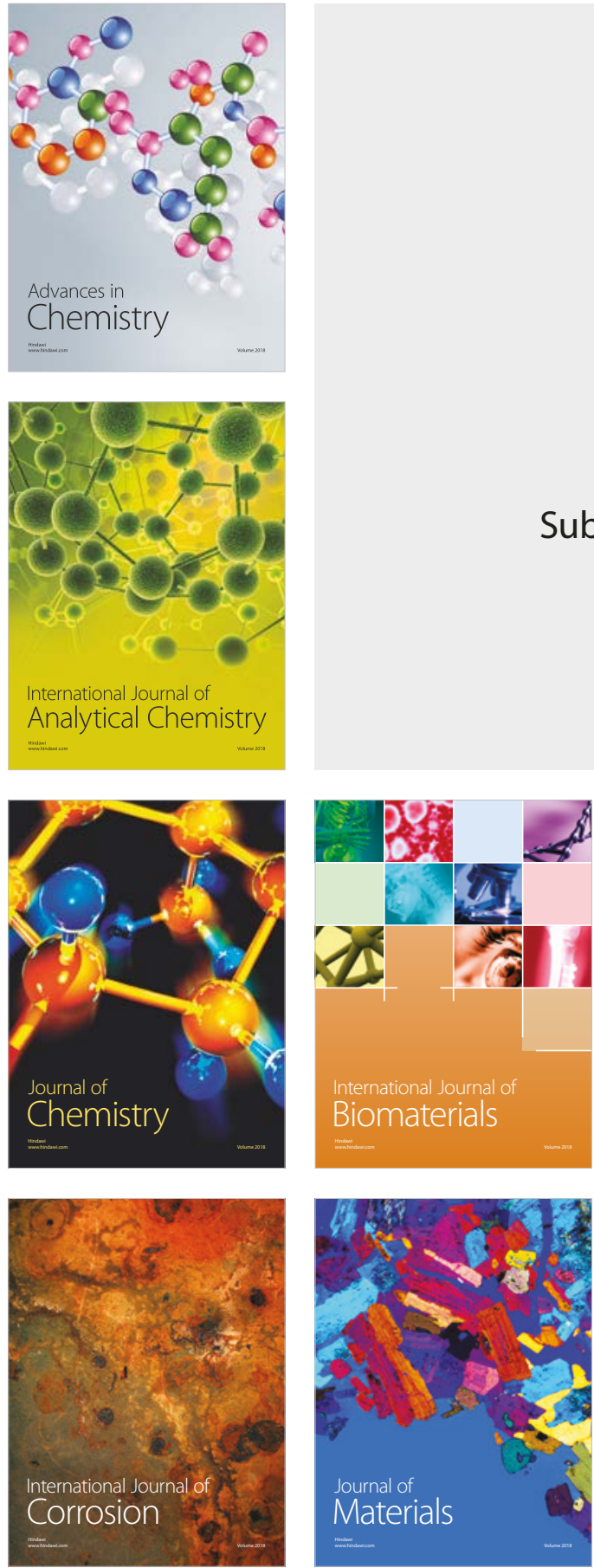

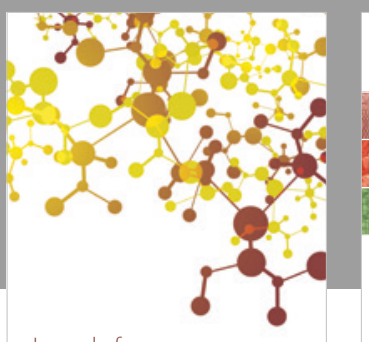

Journal of

Applied Chemistry
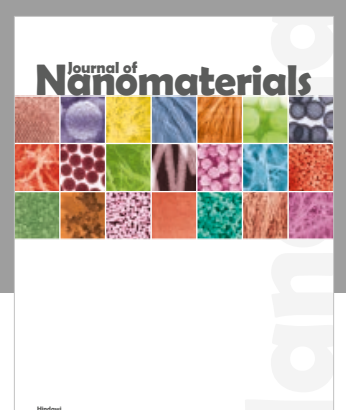

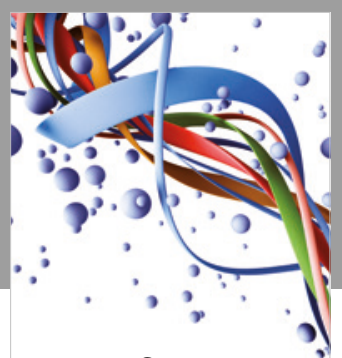

Scientifica

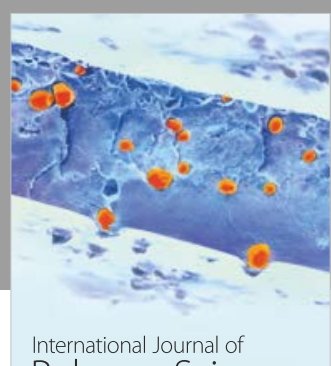

Polymer Science

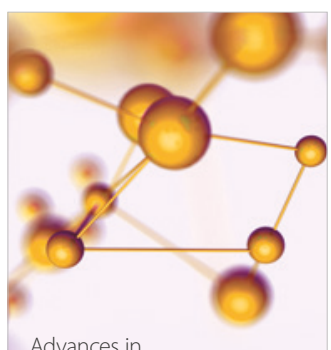

Physical Chemistry
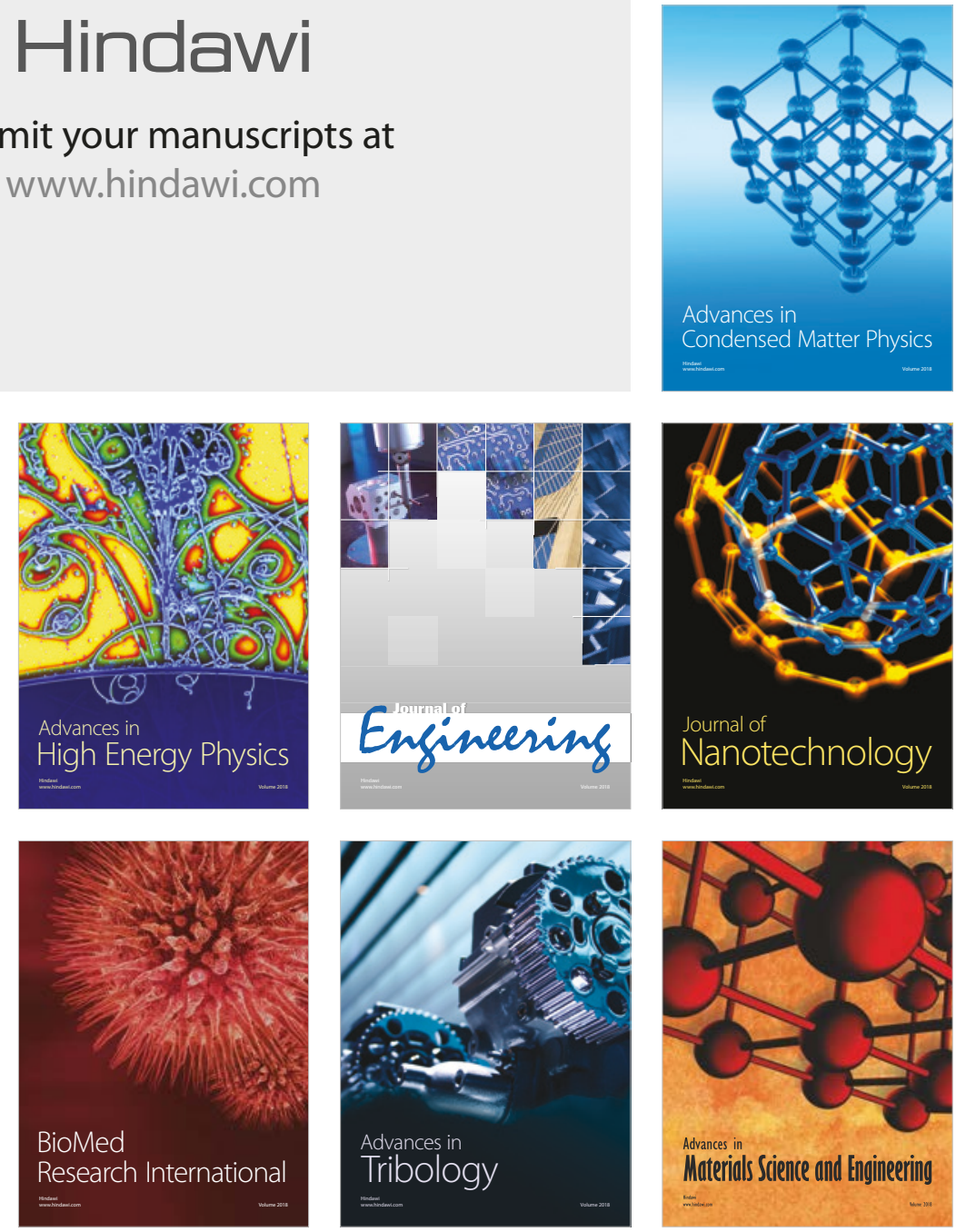